\title{
Flow-Mediated Vasodilation
}

National Cancer Institute

\section{Source}

National Cancer Institute. Flow-Mediated Vasodilation. NCI Thesaurus. Code C124262.

The percent change in arterial vessel diameter in response to an increase in blood flow caused by mechanical or chemical stimuli, which is usually measured using ultrasoundbased methods. This measurement can reflect the functionality of the endothelium in the observed blood vessels. 